\title{
Identifying factors contributing to child and family outcome 30 months after traumatic brain injury in children
}

\author{
V A Anderson, C Catroppa, F Haritou, S Morse, J V Rosenfeld
}

J Neurol Neurosurg Psychiatry 2005;76:401-408. doi: 10.1136/jnnp.2003.019174

See end of article for authors' affiliations

.....................

Correspondence to: Professor V Anderson, Department of Psychology, Royal Children's Hospital, Flemington Road, Victoria, 3052, Australia;

v.anderson@vaa.animels. edu.au

Received 21 May 2003

Accepted 15 June 2004

\begin{abstract}
Objective: To examine the contributions of injury severity, physical and cognitive disability, child and family function to outcome 30 months after traumatic brain injury (TBI) in children.

Design: A prospective, longitudinal, between group design, comparing function before and after injury across three levels of injury severity.

Subjects: One hundred and fifty children, 3.0-12.11 years old, admitted to hospital with a diagnosis of TBI. The sample was divided according to injury severity: mild $(n=42)$, moderate $(n=70)$, severe $(n=38)$. Children with a history of neurological, developmental, and psychiatric disorders were excluded from participation.

Main outcome measures: Post injury physical function, cognitive ability (incorporating intellect, memory, and attention), behavioural and family functioning, and level of family burden.

Results: A dose-response relation was identified for injury severity and physical and cognitive outcome, with significant recovery documented from acute to six months after TBI. Behavioural functioning was not related to injury severity, and where problems were identified, little recovery was noted over time. Family functioning remained unchanged from preinjury to post injury assessments. The level of family burden was high at both six and 30 months after injury, and was predicted by injury severity, functional impairment, and post injury child behavioural disturbance.

Conclusions: These results suggest ongoing problems for the child and significant family burden 30 months after TBI. The nature and severity of the physical and cognitive problems are closely related to injury severity, with child and family function predicted by psychosocial and premorbid factors.
\end{abstract}

behavioural impairment. ${ }^{80}{ }^{32}{ }^{34-36}$ Rutter et al report that, in their study, over half of the children with preinjury psychiatric disorders developed a clinical disorder by 12 months after TBI. ${ }^{29}{ }^{30}$ In contrast, more than half of the children with no pre-existing problems remained symptom free.

The consequences of stress on family function are reflected by increased rates of post injury psychiatric disturbance, family disruption, and divorce..$^{17}{ }^{27} 3033$ 36-38 Conversely, the best outcomes are associated with good social support and family cohesion. Rivara and colleagues ${ }^{15}$ argue that family cohesion and low parental control predict good adaptive functioning, social competence, and global functioning one year after injury. Furthermore, Wade and associates ${ }^{32}$ report that perceived family burden and parental problems after injury occur more frequently in families with chronic stress and maladaptive coping styles. ${ }^{16} 33$

In summary, although injury factors are crucial for predicting the outcome of childhood TBI, other factors must be considered. Our study used a prospective, longitudinal design to document recovery and examine the contributions of injury variables, developmental factors, preinjury child and

Abbreviations: $\mathrm{CT}$, computed tomography; FBII, Family Burden of Injury Interview; FFD, Freedom from Distractibility; FFS, Family Functioning Scales; FSIQ, Full Scale IQ; GCS, Glasgow Coma Scale score; GOS, Glasgow Outcome Scale; MRI, magnetic resonance imaging; MTBI, mild traumatic brain injury; ModTBI, moderate traumatic brain injury; PIC, Personality Inventory for Children; PIQ, Performance IQ; RBRI, Rowe Behavioural Rating Inventory; SES, socioeconomic status; SLT, Spatial Learning Test; SRT, Story Recall Test; SS, scaled score/standard score; STBI, severe traumatic brain injury; TBI, traumatic brain injury; VABS, Vineland Adaptive Behavior Scale; VIQ, Verbal IQ; VLT, Visual Learning Test; WISC-III, Wechsler Intelligence Scale for Children-III; WPPSI-R, Wechsler Preschool and Primary Intelligence Scale-Revised pre-existing vulnerabilities. Preinjury behavioural dysfunction has been found to increase the risk of post injury 
family function, and post injury physical, cognitive, and behavioural skills to acute and longterm outcomes for the child and family. It was expected that severe TBI would be associated with greater impairment acutely and at 30 months after injury, with significant recovery over a 30 month period. Furthermore, it was predicted that injury severity, degree of post injury disability, developmental level, preinjury child and family functioning, and post injury family stress would each contribute to child and family function at 30 months after injury.

\section{METHODS}

\section{Participants}

Children with TBI were recruited from consecutive admissions to the neurosurgical ward of the Royal Children's Hospital, Melbourne, Australia, between 1993 and 1997. Inclusion criteria were: (1) age at injury 3.0-12.11 years; (2) evidence of TBI, including period of altered consciousness (that is, period of confusion, disorientation, and post traumatic amnesia); (3) completion of acute and 30 month evaluations. Exclusion criteria were: TBI as a result of abuse; penetrating head injury; previous $\mathrm{TBI}$; and pre-existing physical, neurological, psychiatric, or developmental disorder.

During the recruitment period, 192 children were admitted with TBI. Fifteen were not eligible because of pre-existing developmental, behavioural, or neurological problems $(\mathrm{n}=11)$; previous TBI $(\mathrm{n}=3)$; or TBI as a result of abuse $(\mathrm{n}=1)$. One hundred and seventy seven children and families were approached, with 27 declining to participate. One child completed only the acute assessment. The resultant sample comprised 150 children: 104 boys and 46 girls. Children were classified into "severity" groups, using the Glasgow Coma Scale score (GCS). ${ }^{39}$

(1) Mild (MTBI; $\mathrm{n}=42$ ): GCS on admission, 13-15; no evidence of mass lesion on computed tomography (CT)/ magnetic resonance imaging (MRI), and no neurological deficits.
(2) Moderate (ModTBI; $\mathrm{n}=70$ ): GCS on admission, 9-12; mass lesion or other evidence of specific injury.

(3) Severe (STBI; $n=38$ ): GCS on admission, 3-8; mass lesion or other evidence of specific injury.

Table 1 presents the demographic, preinjury, and injury data for the sample.

\section{Measures}

\section{TBI outcome}

Admission GCS was recorded by the admitting medical officer. Neurological observations were noted half hourly, extending to four hourly, and continuing until the child regained consciousness. CT/MRI scans were reported by a paediatric neuroradiologist and neurosurgeon, blind to injury severity. The Glasgow Outcome Scale $(\mathrm{GOS})^{40}$ was used to determine physical outcome, acutely and at 30 months after injury.

\section{Parent questionnaires: preinjury, six and 30 months} after TBI

Medical history, developmental history, parent education and occupation, and family constellation were noted. Socioeconomic status (SES) was coded via Daniels Scale of Occupational Prestige, ${ }^{41}$ with high scores representing low SES.

The following measures were completed by parents on admission, recording children's preinjury function, and again at six and 30 months after injury.

(1) Adaptive functioning: Vineland Adaptive Behavior Scale ${ }^{42}$ (VABS; Total Adaptive Behavior, Communication, Daily Living Skills, Socialisation; mean, 100; SD, 50).

(2) Behavioural functioning: Rowe Behavioural Rating Inventory ${ }^{43}$ (RBRI; 8-12 year olds), and Personality Inventory for Children ${ }^{44}$ (PIC; younger than 8 years). Each measure has a mean of 50 (SD, 10), with a higher score indicating greater disturbance.

Table 1 Demographic, preinjury, and injury characteristics of sample

\begin{tabular}{|c|c|c|c|}
\hline & Mild TBI $(n=42)$ & Moderate TBI $(n=70)$ & Severe TBI $(n=38)$ \\
\hline \multicolumn{4}{|l|}{ Demographic characteristics } \\
\hline Number of boys & 27 & 51 & 26 \\
\hline Mean (SD) age at injury (years) & $8.4(3.0)$ & $7.6(2.9)$ & $7.8(3.4)$ \\
\hline Mean (SD) age at testing (years) & $10.3(2.7)$ & $9.6(2.8)$ & $10.0(3.0)$ \\
\hline Mean (SD) SES & $4.1(0.9)$ & $4.4(0.9)$ & $4.6(1.1)$ \\
\hline \multicolumn{4}{|l|}{ Preinjury characteristics } \\
\hline Mean (SD) adaptive ability & $108.8(16.3)$ & $107.04(17.4)$ & $105.6(16.5)$ \\
\hline Mean (SD) behavioural function & $49.9(14.2)$ & $48.2(13.6)$ & $46.8(11.6)$ \\
\hline Mean (SD) family function & $63.7(10.8)$ & $65.8(6.0)$ & $65.5(6.3)$ \\
\hline Number $(\%)$ with intact family unit & $37(88.1)$ & $56(80.0)$ & $22(57.9)$ \\
\hline \multicolumn{4}{|l|}{ Coma characteristics } \\
\hline Mean (SD) GCS on admission* & $14.1(1.3)$ & $11.0(3.3)$ & $5.6(2.2)$ \\
\hline Mean (SD) GCS at 24 hours* & $(0.8)$ & $13.2(2.2)$ & $7.2(2.6)$ \\
\hline \multicolumn{4}{|l|}{ Duration of coma* } \\
\hline None (n (\%)) & $42(100.0)$ & $32(45.7)$ & - \\
\hline$<1$ hour (n (\%)) & - & $23(32.9)$ & $2(5.3)$ \\
\hline $1-24$ hours (n (\%)) & - & 15 (21.4) & $9(23.7)$ \\
\hline$>24$ hours (n (\%)) & - & $1(1.4)$ & $28(71.0)$ \\
\hline Number $(\%)$ with surgical intervention* & & $28(54.9)$ & $22(75.9)$ \\
\hline Number $(\%)$ with abnormal CT/MRI* & - & $58(82.9)$ & $38(100.0)$ \\
\hline Number $(\%)$ with neurological abnormalities* & - & $24(34.3)$ & 28 (73.7) \\
\hline \multicolumn{4}{|l|}{ Cause of injury } \\
\hline MCA: passenger (n (\%)) & $2(4.8)$ & $10(14.3)$ & $8(21.1)$ \\
\hline MCA: pedestrian (n (\%)) & $5(11.9)$ & $11(15.7)$ & $24(63.1)$ \\
\hline Fall (n (\%)) & 31 (73.7) & 36 (51.4) & 5 (13.2) \\
\hline Blow/knock (n (\%)) & $4(9.6)$ & $13(18.6)$ & $1(2.6)$ \\
\hline \multicolumn{4}{|c|}{$\begin{array}{l}\text { Adaptive ability was measured by the Vineland Adaptive Behavior Total Score; Behavioural function was measured by the Personality Inventory for Children/Rowe } \\
\text { Behavioural Rating Inventory; Family Function was measured by the Family Functioning Questionnaire, Intimacy factor; } \\
\text { "p }<0.001 \text {. } \\
\text { CT, computed tomography; GCS, Glasgow Coma Score; MCA, motor car accident; MRI, magnetic resonance imaging; SES, socioeconomic status, assessed by } \\
\text { Daniel's Scale of Occupational Prestige. }\end{array}$} \\
\hline
\end{tabular}


(3) Family Functioning Scales (FFS) ${ }^{45}$ : measures parenting style, with a higher score reflecting more of that characteristic. The Intimacy factor was used in analyses because of its high correlation with other factors

(4) Family Burden of Injury Interview ${ }^{19}$ (FBII; Total Burden, Child, Spouse, Others, Siblings, Family Routines/ Planning scores) (six and 30 months).

\section{Child evaluations: acute and 30 months after injury}

(1) Intelligence: Wechsler Preschool and Primary Intelligence Scale-Revised (WPPSI-R) ${ }^{46}$ or Wechsler Intelligence Scale for Children-III (WISC-III), ${ }^{47}$ depending on age of the child. Verbal (VIQ), Performance (PIQ) and Full Scale (FSIQ) scores were derived (mean, 100; SD, 15).

(2) Attention: Freedom from Distractibility (FFD $)^{48}$ was derived as follows: WPPSI-R: mean of scaled scores for Animal Pegs, Sentences, and Arithmetic subtests; and WISC-III: means of scaled scores for Coding, Digit Span, and Arithmetic.

(3) Memory: Story Recall (SRT) ${ }^{49} 50$ examined verbal learning. Spatial memory was measured using the Spatial Learning Test (SLT) ${ }^{51}$ (children 3 to 7 years) or Visual Learning (VLT: Wide Range Assessment of Memory and

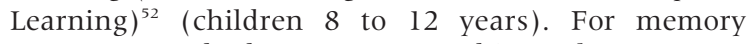
measures standard scores were used in analyses.

\section{Procedure}

Children were enrolled in our study during hospital admission. Parents provided written consent, consistent with hospital ethics procedures. At that time, parent questionnaires (VABS, PIC/RBRI, and FFS) were completed based on preinjury status. These measures were repeated six and 30 months after injury. The FBII was completed at six and 30 months. Children were evaluated once acute neurological dysfunction/post traumatic amnesia had resolved, and not less than two weeks after any surgical intervention (range, 0-3 months after TBI). Follow up evaluations were conducted at six and 30 months after TBI.

Impairment categories for functional domains (physical function (GOS), adaptive behaviour (VABS), child behaviour (RBRI/PIC), family function (FFS), intelligence (FSIQ), memory (SRT, SLT/VLT), and attention (FFD)) were derived as follows: (i) intact: scaled score/standard score (SS), $\geqslant 1$ SD above test mean; (ii) mild impairment: SS 1-2 SD below test mean; (iii) moderate impairment: SS 2-3 SD below test mean; (iv) severe impairment: SS $>3$ SDs below test mean.

\section{Statistical analysis}

Initial analyses examined associations between severity (mild, moderate, and severe) and recovery for each functional domain over time after injury (preinjury/acute, six, and 30 months), using repeated measures multivariate analysis of variance. Where significant effects were identified, post hoc analyses were conducted. Wilcoxin signed ranks tests were used to identify group differences for level of disability across functional domains and time points. To determine predictors of 30 month outcome, multiple regressions were conducted within each functional domain. Correlations among independent variables were calculated, to identify multicollinearity. As a result, predictors of outcome used in all analyses included injury severity, injury age, and SES. Additional predictors were included according to the domain under examination, and included preinjury child and family function (VABS, PIC/RBRI, FFS), and acute post injury abilities (FSIQ, FFD, FBII).

\section{RESULTS}

\section{Demographic and injury variables}

There were no group differences with respect to injury age, sex, SES, preinjury adaptive functioning, behaviour, or family function. Group differences for injury severity were significant, with children sustaining STBI recording lower GCS scores on admission ( $p<0.001$ ), and at 24 hours after injury $(p<0.001)$, a longer duration of loss of consciousness $(p<0.001)$, a higher risk of neurological symptoms $(p<0.001)$, abnormalities on CT/MRI scan $(p<0.001)$, and more surgical interventions $(p<0.001)$. Whereas children with modTBI and STBI had a similar risk of localised brain pathology $(32.7 \%$ and $27.7 \%$, respectively), those with STBI were more likely to suffer generalised brain injuries (modTBI, 25.7\%; STBI, 63.1\%). For the STBI sample, mean length of hospital stay was 38.4 days (SD, 25.7; range, 3-111).

\section{Injury severity and functional outcome}

(1) Intellectual ability: repeated measures ANOVA revealed consistent severity effects (FSIQ: $F(2,149)=13.11$; $\mathrm{p}<0.001$; VIQ: $\mathrm{F}(2,149)=6.89 ; \mathrm{p}=0.001$; PIQ: $\mathrm{F}(2,149)=12.87 ; \mathrm{p}<0.001)$, with the STBI group performing worse at all time points. For FSIQ and PIQ, both a significant time effect $(\mathrm{F}(2,149)=010.4$; $\mathrm{p}<0.001, \mathrm{~F}(2,149)=25.16 ; \mathrm{p}<0.001$, respectively $)$, and a significant time $\times$ severity interaction were found $(\mathrm{F}(5,149)=2.80 ; \mathrm{p}<0.05 ; \mathrm{F}(5,149)=3.43 ; \mathrm{p}<0.01$, respectively). As illustrated in table 2, for FSIQ and PIQ, the mean scores for the MTBI group changed little from acute to 30 month assessments. In contrast, significant increments were evident between acute and six month assessments for modTBI and STBI, with scores stable from six to 30 months after injury.

(2) Attention: analysis of FFD scores identified significant effects for severity $(\mathrm{F}(2,149)=8.2 \mathrm{l} ; \mathrm{p}<0.001)$ and time $(\mathrm{F}(2,149)=5.43 ; \mathrm{p}<0.01)$. Greater injury severity was associated with worse performance at all time points, with the time effect explained by a significant increase in the scores of the STBI group between the acute stage and six months after injury.

(3) Memory: although the ranking of age standardised scores was consistent with the hypothesised effect, analyses revealed no significant group effect, and no severity $\times$ time interaction. Performances did change with time (Verbal: $\mathrm{F}(2,149)=11.60 ; \mathrm{p}<0.001 ;$ Spatial: $\mathrm{F}(2,149)=9.82$; $\mathrm{p}<0.001)$ because of a general improvement in performance from acute to six months assessments, possibly explained by a combination of practice effects and recovery. In contrast, results from six to 30 months were comparable. Of note, spatial memory scores were intact for all groups, at all assessments, with mean scores falling consistently within the average range. Verbal memory skills remained below expectations for the duration of the follow up.

\section{Adaptive function}

As illustrated in table 2, there was a significant time effect for the VABS $(\mathrm{F}(2,149)=9.20 ; \mathrm{p}<0.001)$, with all groups recording a decline in scores from preinjury to 30 months after injury. Severity and time $\times$ severity effects approached significance $(p=0.08)$, with children sustaining STBI tending to record a greater decline in adaptive abilities. For VABS subscales, similar trends were seen for the Daily Living Skills and Socialisation domains, where a main effect of time $(\mathrm{F}(2,149)=5.36 ; \mathrm{p}<0.01 ; \mathrm{F}(2,149)=9.77 ; \mathrm{p}<0.001$, respectively) and an interaction effect $(\mathrm{F}(4,149)=2.51$; $\mathrm{p}<0.05 ; \mathrm{F}(4,149)=3.64 ; \mathrm{p}<0.01$, respectively) were 
Table 2 Baseline/acute, six, and 30 months functional performances across severity groups

\begin{tabular}{|c|c|c|c|c|c|c|c|c|c|}
\hline & \multicolumn{3}{|c|}{ Mild TBI $(n=42)$} & \multicolumn{3}{|c|}{ Moderate TBI $(n=70)$} & \multicolumn{3}{|c|}{ Severe TBI $(n=38)$} \\
\hline & Acute & 6 months & 30 months & Acute & 6 months & 30 months & Acute & 6 months & 30 months \\
\hline \multicolumn{10}{|l|}{ Child evaluations } \\
\hline $\mathrm{FSIQ}^{*} \dagger^{* *} \ddagger \S+$ & $102.9(2.3)$ & $103.7(2.2)$ & $102.9(2.3)$ & $94.9(1.8)$ & $97.2(1.8)$ & $97.4(1.8)$ & $82.6(2.6)$ & $88.5(2.5)$ & $88.3(2.6)$ \\
\hline $\mathrm{VIQ} Q^{* * *} \dagger$ & $98.5(2.2)$ & $98.2(2.0)$ & $96.5(2.2)$ & $93.9(1.6)$ & $93.6(1.6)$ & $93.1(1.7)$ & $85.6(2.5)$ & $87.7(2.3)$ & $86.5(2.4)$ \\
\hline $\mathrm{PIQ}^{* *} \dagger^{* * \star} \neq \S$ & $110.5(2.6)$ & $109.4(2.7)$ & 110.1 (2.7) & $97.4(2.1)$ & $102.0(2.1)$ & $102.8(2.1)$ & $83.0(3.0)$ & $92.8(3.1)$ & $93.5(3.1)$ \\
\hline Attention: FFD ${ }^{* *} \dagger^{* * *} \ddagger$ & $10.4(0.4)$ & $10.6(0.3)$ & $10.5(0.4)$ & $9.2(0.3)$ & $9.3(0.3)$ & $9.6(0.3)$ & $7.8(0.5)$ & $8.8(0.4)$ & $8.9(0.4)$ \\
\hline Verbal Mem: SS ${ }^{* * *} \ddagger$ & $-1.52(0.4)$ & $-0.40(0.2)$ & $-0.41(0.2)$ & $-1.37(0.4)$ & $-0.50(0.2)$ & $-0.74(0.1)$ & $-1.58(0.5)$ & $-0.8(0.2)$ & $-0.45(0.2)$ \\
\hline Spatial Mem: SS $S^{* * *} \mp$ & $0.08(0.2)$ & $0.70(0.3)$ & $0.65(0.2)$ & $-0.13(0.1)$ & $0.60(0.2)$ & $0.29(0.1)$ & $-0.48(0.8)$ & $-0.1(0.4)$ & $0.23(0.2)$ \\
\hline \multicolumn{10}{|l|}{ Parent measures } \\
\hline VABS: Total ${ }^{* * *} \ddagger$ & $107.3(3.2)$ & $109.1(3.6)$ & $104.7(3.2)$ & $104.8(2.6)$ & $100.1(2.9)$ & $98.5(2.6)$ & $102.5(4.7)$ & $92.5(5.3)$ & $90.3(4.7)$ \\
\hline Communication ${ }^{* *} \dagger \ddagger$ & 109.1 (2.9) & $108.2(3.0)$ & $106.1(3.1)$ & $102.3(2.3)$ & $98.5(2.5)$ & $98.8(2.5)$ & $101.1(4.2)$ & $91.9(4.3)$ & $92.5(4.5)$ \\
\hline Daily Living ${ }^{*}{ }^{* \star \S}$ & $102.5(2.6)$ & $106.4(3.2)$ & $99.5(2.6)$ & $101.4(2.1)$ & $98.9(2.6)$ & $99.0(2.1)$ & $98.8(3.9)$ & $94.2(4.7)$ & $90.2(3.7)$ \\
\hline Socialisation ${ }^{* *} \ddagger^{\star * *} \S$ & $104.4(3.1)$ & $105.8(3.5)$ & $104.6(2.8)$ & $106.6(2.5)$ & $100.4(2.8)$ & 99.1 (2.3) & $104.9(4.4)$ & $93.4(5.0)$ & $91.4(4.0)$ \\
\hline FFS: Intimacy & $62.7(1.5)$ & $62.6(1.4)$ & $61.7(1.6)$ & $66.7(1.3)$ & $65.6(1.3)$ & $65.2(1.4)$ & $65.4(2.1)$ & $67.1(2.0)$ & $66.6(2.2)$ \\
\hline FBII: Total score ${ }^{* * *} \dagger$ & & $0.68(0.3)$ & $0.58(0.4)$ & - & $1.11(0.2)$ & $1.33(0.3)$ & - & $2.15(0.5)$ & $2.87(0.7)$ \\
\hline Child ${ }^{* * *} \dagger$ & - & $0.31(0.1)$ & $0.31(0.1)$ & - & $0.58(0.1)$ & $0.66(0.1)$ & - & $1.4(0.2)$ & $1.6(0.2)$ \\
\hline Spouse ${ }^{* * *} \dagger$ & - & $0.18(0.1)$ & $0.04(0.1)$ & - & $0.10(0.1)$ & $0.19(0.1)$ & - & $0.38(0.1)$ & $0.63(0.1)$ \\
\hline Others ${ }^{* * *} \dagger$ & - & $0.06(0.1)$ & $0.01(0.1)$ & - & $0.06(0.1)$ & $0.01(0.1)$ & - & $0.59(0.1)$ & $0.64(0.1)$ \\
\hline Siblings ${ }^{*} \dagger^{* * *} \ddagger$ & - & $0.13(0.1)$ & $0.13(0.1)$ & - & $0.17(0.1)$ & $0.15(0.1)$ & - & $0.93(0.2)$ & $1.06(0.1)$ \\
\hline Routine/plan ${ }^{\star * *} \dagger$ & - & $0.55(0.1)$ & $0.09(0.1)$ & - & $0.18(0.1)$ & $0.18(0.1)$ & - & $0.95(0.1)$ & $1.10(0.2)$ \\
\hline
\end{tabular}

${ }^{*} \mathrm{p}<0.05 ;{ }^{* *} \mathrm{p}<0.01 ;{ }^{* * *} \mathrm{p}<0.001$; †significant severity effect; $\ddagger$ significant time effect; $\S$ significant severity $\times$ time effect.

FBII, Family Burden Inventory; FFD, Freedom from Distractibility; FFS, Family Function Scale; FSIQ, Full Scale IQ; Mem, memory; PIQ, Performance IQ; SS, standard score; TBI, traumatic brain injury; VABS, Vineland Adaptive Behaviour Scales; VIQ, Verbal IQ.

detected. In each case, although preinjury scores were indistinguishable across severity groups, modTBI and STBI groups showed a fall off in scores at six months after injury, with these group differences being maintained at the 30 month evaluation. For communication, main effects were seen with both severity $(\mathrm{F}(2,149)=4.94 ; \mathrm{p}=0.001)$ and time $(\mathrm{F}(2,149)=4.88 ; \mathrm{p}<0.01)$. No significant interaction effect was found, although for the MTBI group, preinjury communication scores tended to be higher than for the other groups, and remained unchanged after injury. The modTBI and STBI groups showed a trend for poorer communication scores from preinjury to six months after injury.

\section{Child behaviour}

No severity effect was identified, although the result approached significance $(\mathrm{p}=0.06)$. There were significant effects of time $(\mathrm{F}(2,149)=10.09 ; \mathrm{p}<0.001)$ and time $\times$ severity $(\mathrm{F}(4,149)=6.63 ; \mathrm{p}<0.001)$. The scores suggest that all groups had similar values before injury, with scores reflecting a below average frequency of problem behaviours. Although the MTBI group maintained this level of function, children with modTBI and STBI displayed significant increases in behavioural symptoms from preinjury to post injury evaluations, with this higher level of problem behaviour being maintained from six to 30 months. Although there was some within group variation, group mean scores consistently fell within or below the average range.

\section{Family function}

Group scores on the FFS were stable over all time points. In contrast, a highly significant effect of injury severity was detected for the Total score for the FBII $(\mathrm{F}(2,149)=7.83$; $\mathrm{p}<0.001$ ), with group differences also evident on the Child $(\mathrm{F}(2,149)=11.04 ; \mathrm{p}<0.001)$, Spouse $(\mathrm{F}(2,149)=8.14$; $\mathrm{p}<0.001)$, Others $(\mathrm{F}(2,149)=10.87 ; \mathrm{p}<0.001)$, Siblings

Table 3 Pattern of deficits after injury: acute and 30 months

\begin{tabular}{|c|c|c|c|c|c|c|c|}
\hline \multirow[b]{2}{*}{ Functional domain } & \multirow[b]{2}{*}{ Degree of impairment } & \multicolumn{2}{|c|}{ Mild TBI ( $n=42)$} & \multicolumn{2}{|c|}{ Moderate TBI $(n=70)$} & \multicolumn{2}{|c|}{ Severe TBI $(n=38)$} \\
\hline & & $\begin{array}{l}\text { Acute } \\
(\%)\end{array}$ & $\begin{array}{l}30 \text { months } \\
(\%)\end{array}$ & $\begin{array}{l}\text { Acute } \\
\text { (\%) }\end{array}$ & $\begin{array}{l}30 \text { months } \\
(\%)\end{array}$ & $\begin{array}{l}\text { Acute } \\
(\%)\end{array}$ & $\begin{array}{l}30 \text { months } \\
(\%)\end{array}$ \\
\hline \multirow[t]{3}{*}{ Physical $^{* *}$} & Good recovery & 88.1 & 97.6 & 54.3 & 77.1 & 12.9 & 57.9 \\
\hline & Moderate disability & 11.9 & 2.4 & 44.3 & 22.9 & 61.3 & 31.6 \\
\hline & Severe disability & - & - & 1.4 & - & 25.8 & 10.5 \\
\hline \multirow[t]{4}{*}{ Intellectual ${ }^{*}$} & Intact & 90.5 & 97.4 & 76.5 & 78.5 & 60.9 & 54.3 \\
\hline & Mild deficit & 9.5 & 2.6 & 21.6 & 20.0 & 17.4 & 34.3 \\
\hline & Moderate deficit & - & - & 1.9 & 1.5 & 17.4 & 11.4 \\
\hline & Severe deficit & - & - & - & - & 4.3 & - \\
\hline \multirow[t]{4}{*}{ Memory } & Intact & 66.7 & 79.5 & 60.0 & 62.3 & 33.3 & 44.9 \\
\hline & Mild deficit & 22.2 & 17.9 & 31.1 & 27.9 & 37.5 & 20.7 \\
\hline & Moderate deficit & 11.1 & 2.6 & 8.9 & 8.2 & 4.2 & 31.0 \\
\hline & Severe deficit & - & - & - & 1.6 & 25.0 & 3.4 \\
\hline \multirow[t]{4}{*}{ Attention } & Intact & 96.4 & 92.3 & 90.0 & 83.1 & 60.0 & 76.5 \\
\hline & Mild deficit & 3.6 & 7.7 & 8.0 & 16.9 & 35.0 & 14.7 \\
\hline & Moderate deficit & - & - & 2.0 & - & 5.0 & 8.8 \\
\hline & Severe deficit & - & - & - & - & - & - \\
\hline \multirow[t]{4}{*}{ Behaviour* } & Intact & 85.7 & 80.5 & 79.2 & 59.3 & 85.7 & 50.0 \\
\hline & Mild deficit & 3.6 & 13.9 & 8.2 & 27.8 & 9.5 & 15.4 \\
\hline & Moderate deficit & 7.1 & 2.8 & 6.3 & 7.4 & - & 23.1 \\
\hline & Severe deficit & 3.6 & 2.8 & 6.3 & 5.5 & 4.8 & 11.5 \\
\hline
\end{tabular}


$(\mathrm{F}(2,149)=19.93 ; \mathrm{p}<0.001)$, and Family Routines/Planning $(F(2,149)=20.85 ; p<0.001)$ subscales. Families of children with STBI consistently reported higher levels of family burden. No time or time $\times$ severity effects were found for the Total, Child, Other, or Family Routines/Planning subscales. For the Siblings subscale, a time effect was identified $(\mathrm{F}(2,149)=$ 3.77; $\mathrm{p}<0.05$ ), with each group showing a greater burden at 30 months. A time $\times$ severity interaction was noted for the Spouse subscale $(\mathrm{F}(2,149)=2.21 ; \mathrm{p}<0.05)$, with increasing burden detected from six to 30 months for the modTBI and STBI groups only. These last results suggest that, as the child recovers, the stresses of other family relationships may become more evident.

\section{Frequency of functional deficits}

Table 3 lists the proportion of children from each severity group exhibiting deficits in functional domains, and the associated degree of impairment. For the total sample there was a significant decrease, from acute to 30 months, in the proportion of children showing physical $(z=-5.17$; $\mathrm{p}<0.001)$ and intellectual impairments $(z=-2.68$; $\mathrm{p}<0.01)$. Within the MTBI group, no significant differences were noted over time in the functional domains, perhaps reflecting the lack of substantive impact of injury for this group. For the modTBI group, physical impairment was the single domain to record change $(z=-3.27 ; p=0.001)$, with a smaller proportion of children exhibiting physical problems by 30 months after injury (acute, 45.8\%; 30 months, $22.9 \%$ ). Although not significant, the increase in behavioural problems in this group is of interest. Preinjury levels were around $20 \%$, and by 30 months post injury $40 \%$ of the group exhibited behavioural difficulties. In contrast, for the STBI group, although the frequency of memory difficulties remained stable, significant recovery occurred for the physical $(z=-3.63 ; \mathrm{p}<0.001)$, intellectual $(z=-2.55$; $\mathrm{p}=0.01)$, and attention domains $(z=-2.18 ; \mathrm{p}=0.05)$. For behaviour, where the comparisons were from preinjury to 30 months after injury, the frequency of children with STBI displaying problems showed a significant increase $(z=-2.69 ; \mathrm{p}<0.01)$, from $14.9 \%$ to $50.0 \%$.

Table 4 provides a breakdown of the number of children with moderate to severe deficits across groups and time. Chi square analysis identified substantial group differences $\left(\chi^{2}(8)=38.3 ; \mathrm{p}<0.001\right)$. For the MTBI group, children exhibited normal functioning or a single impairment at both time points (97.6\% and $98.7 \%$, respectively). Less than $10 \%$ of the modTBI group displayed difficulties in more than one domain by 30 months after injury. Within the STBI group, although there was some reduction in disability, $36.8 \%$ of children continued to show moderate/severe impairments in two or more domains at 30 months after injury, reflecting the more severe, generalised nature of functional sequelae experienced by these children.

\section{Predictors of outcome of child TBI}

Regression analyses were carried out to establish the contribution of injury and preinjury factors to post injury outcome. All analyses included age at injury, injury severity, and SES. Additional predictors were included in the regression model: family function (FFS and FBII at 30 months), behaviour (RBRI/PIC at 30 months), ability level (FSIQ, VABS), and attention (FFD). Overall, as illustrated in table 5, regression models failed to explain a large proportion of the variance for all the measures.

\section{Child function}

Intellectual abilities at 30 months after injury were predicted by SES and FFD, with a smaller contribution of injury severity $(p=0.07)$. The regression equation was able to explain $47 \%$ of the variance for this domain. SES was also found to predict attentional function at 30 months, along with FSIQ $\left(R^{2}=0.30\right)$. A different set of predictors was identified for the behavioural domains. Adaptive behaviour (VABS) was explained by a combination of injury age and injury severity and, to a lesser extent, preinjury child behaviour ( $\mathrm{p}=0.08$ ), with $44 \%$ of the variance explained. For 30 month behavioural function (RBRI/PIC), there was no significant relation with injury factors; however, results were associated with injury age, with preinjury adaptive behaviour (VABS) and post acute family stress (FBII) also being important $\left(R^{2}=0.41\right)$.

\section{Family function}

Family functioning at 30 months was predicted by child behaviour and adaptive function before injury $(p=0.08)$, suggesting that this domain is less vulnerable to injury factors. In contrast, family burden was predicted by injury severity, physical impairment, injury age, and preinjury behaviour, with preinjury adaptive function explaining a smaller proportion of the variance $\left(R^{2}=0.31\right)$.

\section{DISCUSSION}

The broad objective of our study was to document recovery from childhood TBI over 30 months after injury. Furthermore, we investigated the associations among specific functional domains and examined the contribution of a range of injury and non-injury related factors to child and family outcome. Of note, demographic characteristics (age, sex, SES, adaptive function, behaviour, and family function) did not differ across the severity groups, indicating that post injury findings could not be explained in terms of preinjury factors. Results were consistent with previous research, ${ }^{27} 3033$ establishing a strong relation between injury factors and outcome in physical and cognitive domains. Post injury child and family function were less associated with injury factors, and more dependent upon preinjury psychosocial functions, as has also been shown in recent studies. ${ }^{32} 33$ As expected, children sustaining STBI

\begin{tabular}{|c|c|c|c|c|c|c|}
\hline & \multicolumn{2}{|c|}{ Mild TBI $(n=42)$} & \multicolumn{2}{|c|}{ Moderate TBI $(n=70)$} & \multicolumn{2}{|c|}{ Severe TBI $(n=38)$} \\
\hline & Acute & 30 months & Acute & 30 months & Acute & 30 months \\
\hline $\begin{array}{l}\text { No deficits } \\
1 \text { deficit } \\
2 \text { deficits } \\
3 \text { deficits } \\
4 \text { or more deficits }\end{array}$ & $\begin{array}{l}35(83.3) \\
6(14,3) \\
1(2.4) \\
- \\
-\end{array}$ & $\begin{array}{l}38(90.5) \\
4(9.5) \\
- \\
- \\
-\end{array}$ & $\begin{array}{l}39(55.8) \\
25(35.7) \\
5(7.1) \\
- \\
1(1.4)\end{array}$ & $\begin{array}{l}49(70.0) \\
15(21.4) \\
5(7.2) \\
- \\
1(1.4)\end{array}$ & $\begin{array}{l}6(15.8) \\
14(36.8) \\
14(36.8) \\
3(7.9) \\
1(2.6)\end{array}$ & $\begin{array}{l}12(31.6) \\
13(34.2) \\
7(18.4) \\
3(7.9) \\
3(7.9)\end{array}$ \\
\hline \multicolumn{7}{|c|}{$\begin{array}{l}\text { Values are number }(\%) \text {. } \\
\text { Significant group difference: } \chi^{2}(8)=38.3 ; p<0.001 \text {. } \\
\mathrm{TB} \mid \text {, traumatic brain injury. }\end{array}$} \\
\hline
\end{tabular}


Table 5 Predictors of 30 month outcome

\begin{tabular}{|c|c|c|c|c|c|c|c|c|}
\hline Predictor variables & & GOS & VABS & FSIQ & FFD & PIC/RBRI & $\begin{array}{l}\text { Family } \\
\text { function }\end{array}$ & $\mathrm{FBI}$ \\
\hline \multirow[t]{3}{*}{ Injury age } & $\beta$ & & -0.35 & & & -0.21 & & 0.38 \\
\hline & t Value & NS & -2.65 & NS & NS & -1.95 & NS & 3.29 \\
\hline & p Value & & 0.011 & & & 0.057 & & 0.002 \\
\hline \multirow{2}{*}{ Injury severity (GCS) } & & & & & & & & \\
\hline & $\begin{array}{l}\text { † Value } \\
\text { p Value }\end{array}$ & NS & NS & NS & NS & NS & NS & NS \\
\hline \multirow[t]{3}{*}{ Physical impairment (GOS) (acute score) } & $\beta$ & & 0.29 & 0.24 & & & & -0.31 \\
\hline & t Value & - & 1.93 & 1.85 & NS & NS & NS & -1.94 \\
\hline & $\mathrm{p}$ Value & & 0.059 & 0.070 & & & & 0.05 \\
\hline \multirow[t]{2}{*}{ SES } & $\beta$ & & & -0.23 & -0.21 & & & \\
\hline & $\begin{array}{l}\text { t Value } \\
\text { p Value }\end{array}$ & NS & NS & $\begin{array}{l}-2.22 \\
0.030\end{array}$ & $\begin{array}{l}-1.74 \\
0.087\end{array}$ & NS & NS & NS \\
\hline \multirow[t]{3}{*}{ VABS (preinjury score) } & $\beta$ & & & & & -0.28 & 0.24 & 0.22 \\
\hline & t Value & NS & - & NS & NS & -2.41 & 1.70 & 1.74 \\
\hline & $\mathrm{p}$ Value & & & & & 0.020 & 0.095 & 0.088 \\
\hline \multirow[t]{3}{*}{ Family function (FFS) (preinjury score) } & $\beta$ & & & & & -0.22 & & \\
\hline & t Value & NS & NS & NS & - & -1.71 & - & NS \\
\hline & $\mathrm{p}$ Value & & & & & 0.094 & & \\
\hline \multirow[t]{2}{*}{ Family burden (FBII) (acute score) } & $\beta$ & & & & & 0.32 & & \\
\hline & $\begin{array}{l}\text { t Value } \\
\text { p Value }\end{array}$ & NS & NS & NS & NS & $\begin{array}{l}2.54 \\
0.014\end{array}$ & NS & - \\
\hline \multirow[t]{3}{*}{ Behaviour (PIC/RBRI) (preinjury score) } & $\beta$ & & -0.24 & & & & 0.45 & 0.42 \\
\hline & t Value & NS & -1.77 & NS & NS & - & 3.43 & 3.74 \\
\hline & $\mathrm{p}$ Value & & 0.080 & & & & 0.001 & 0.000 \\
\hline \multirow[t]{3}{*}{$I Q$ score (acute score) } & $\beta$ & 0.54 & & & 0.37 & & & \\
\hline & t Value & 3.19 & NS & - & 2.23 & NS & NS & NS \\
\hline & $\mathrm{p}$ Value & 0.02 & & & 0.030 & & & \\
\hline \multirow[t]{3}{*}{ Freedom from Distractibility (acute score) } & $\beta$ & & NS & 0.40 & & & & \\
\hline & $\begin{array}{l}\text { t Value } \\
\mathrm{p} \text { Value }\end{array}$ & NS & & $\begin{array}{l}3.39 \\
0.001\end{array}$ & - & NS & NS & NS \\
\hline & $R^{2}$ & 0.32 & 0.44 & 0.47 & 0.30 & 0.41 & 0.29 & 0.31 \\
\hline
\end{tabular}

FBII, Family Burden of Injury Interview; FFS, Family Functioning Scales; GCS, Glasgow Coma Scale score; GOS, Glasgow Outcome Scale; NS, not significant; PIC, Personality Inventory for Children; RBRI, Rowe Behavioural Rating Inventory; SES, socioeconomic status; VABS, Vineland Adaptive Behaviour Scale.

showed more frequent, severe, and persisting impairments than those with less severe injuries. Although children sustaining modTBI displayed some difficulties in the acute stages, these were largely resolved by 30 months after injury. Children with MTBI exhibited relatively few impairments and little recovery over time, suggesting minimal functional impact of injury.

As expected, ${ }^{356}$ results documented a consistent doseresponse relation with respect to physical and cognitive outcome at 30 months after injury. For physical function, no child with MTBI or modTBI had residual deficits at 30 months after TBI, although moderate/severe ongoing problems were evident in $42 \%$ of children with STBI. Similarly, children sustaining STBI performed worst on measures of intellectual ability and attention. Although mean group scores were within the "low average" range, this may provide an overly positive representation of outcome. At the individual level, the proportion of severely injured children with moderate or severe impairment is substantial (IQ, $11.4 \%$; attention, $8.8 \%$ ), arguing for the importance of careful review of this high risk group. For memory function, group differences did not reach significance: verbal memory function was depressed in all severity groups, with group means falling below expectations at all time points. In keeping with these results, the frequency of ongoing moderate and severe memory deficits was also high (modTBI, 9.8\%; STBI, 34.4\%).

The impact of injury severity was further supported by the relation between severity and the degree of deterioration in adaptive ability from the preinjury and 30 month evaluations. Whereas mildly injured children had stable adaptive ability scores, children with modTBI and STBI recorded a decline in function. Decrements were evident in all areas, suggesting worse post injury communication, socialisation, and daily living skills.
By 30 months after injury, all groups showed an increase in behaviour problems. Clinically important behavioural problems were identified in less than $20 \%$ of the sample, and children with STBI made up just over half of this group (52\%), compared with $36 \%$ from the modTBI group and $12 \%$ from the MTBI group. Parenting style remained stable over time, suggesting no significant impact of injury on preinjury parenting style. In contrast, perceived family burden was strongly associated with injury severity. Families with children with STBI reported higher levels of burden and stress, even at 30 months after injury. Stresses impacted on parents, siblings, and family activities equally. It remains to be seen whether these high levels of family burden eventually translate into global family dysfunction with increasing time since injury.

For children sustaining MTBI, performance was stable for the duration of our study, and mean group scores were consistently normal. This lack of initial "deficit" and subsequent "recovery" is consistent with findings from previous studies evaluating the impact of MTBI in children, ${ }^{363453}$ and may reflect an absence of permanent brain injury, despite the presence of a period of altered consciousness. However, without comparison with an appropriate control group, findings regarding MTBI must be interpreted cautiously.

For children with moderate and severe TBI, changes in function over time support a period of early recovery, with more stable results from six to 30 months after injury. Improvements during the acute period were seen for intelligence, attention, memory, and child behaviour, with mean scores for the STBI group showing the most dramatic increases. These findings are in keeping with adult models, where recovery is steepest in the six months after injury, and continues more slowly until two years after injury. ${ }^{18}$ However, our data do suggest a more truncated recovery trajectory for 
children, with few gains after the acute recovery period. Furthermore, for the psychosocial domain (for example, behaviour, daily living skills, and socialisation), there may be a gradual "deterioration", or lack of expected development in child function during this post acute period, in addition to an increase in family stress. Thus, as physical and cognitive recovery stabilises, psychosocial and behavioural difficulties (possibly indicating adjustment problems) may emerge, with family focus moving from rehabilitation concerns to the ongoing stresses that the child with TBI places on family relationships and activities.

A comparison of the frequency of problems at the acute stage and 30 months after injury suggests most change for physical function, where moderate and severe deficits reduced dramatically over time. Greatest improvements were found for the STBI sample, with only $13.2 \%$ of children rated as having a good recovery acutely, and $57.9 \%$ falling into this category by 30 months. Memory and attention outcomes were similar. For intellectual ability, more children in the mild and moderate TBI groups exhibited intact scores by 30 months, although there was an increase in intellectual impairment overall in the STBI group. For behaviour, mild and moderate TBI groups were stable from the acute stage to the 30 months follow up. In contrast, the percentage of children with STBI falling within the moderate and severe impairment category increased from $4.8 \%$ to $34.6 \%$ by 30 months.

Recovery and outcome from childhood TBI is dependent on a range of factors; however, the combination of parameters used in our study yielded disappointing results, being unable to provide a sufficient model of 30 month outcome. However, of interest was the different pattern of predictors identified for physical and cognitve domains compared with psychosocial functions. For physical and cognitive recovery, injury severity was a consistent predictor, along with SES. Family factors and child behaviour did not enter regression equations. For child and family function, injury severity and acute neurobehavioural performance were unrelated to outcome, whereas preinjury behaviour, adaptive function, post acute family stress, and injury age were predictive, suggesting a reciprocal association among psychosocial factors. Finally, contributors to perceived family burden were more widely distributed, and incorporated a combination of both injury based and psychosocial variables, including injury severity and injury age, in addition to preinjury adaptive ability and behaviour.

In summary, our study has investigated interactions among a range of outcome domains after childhood TBI. In keeping with previous research, results suggest that injury severity is most closely related to longterm physical and neurobehavioural recovery. Post injury child behaviour and family functioning are more loosely linked to injury factors. Similar to adults, children with severe injuries are at high risk of experiencing deficits in a range of functional areas. Those sustaining mild and moderate injuries have a better prognosis, and rarely exhibit persistent impairments. In contrast to adult studies, a truncated recovery curve was identified, with improvements documented only up to six months after injury. Furthermore, in the adaptive and behavioural domains there is evidence of decline, or lack of development, by six months after injury. As might be expected, preinjury factors play a key role in post injury behaviour and family function, suggesting that premorbid vulnerabilities increase the risk of poor outcome after TBI. These findings support the need for accurate identification of injury related and psychosocial risk factors in children and families after TBI, before impairments in multiple domains become entangled and difficult to identify. Evidence of family stress or new child behaviour difficulties may alert professionals to the presence of problems. Early, targeted treatment, for both children and families, may minimise the secondary problems commonly associated with TBI.

\section{ACKNOWLEDGEMENTS}

This research was supported by the Australian National Health and Medical Research Council and the Royal Children's Hospital Research Institute.

\section{Authors' affiliations}

V A Anderson, C Catroppa, University of Melbourne, Melbourne, 3010 Australia

C Catroppa, F Haritou, Murdoch Children's Research Institute, Melbourne, Australia

J V Rosenfeld, Alfred Medical Centre, Melbourne, Australia

Competing interests: none declared

\section{REFERENCES}

1 Kraus JF. Epidemiological features of brain injury in children. In: Broman SH, Michel ME, eds. Traumatic head injury in children. New York: Oxford University Press, 1995: 165-87.

2 Fletcher J, Ewing-Cobbs L, Francis D, et al. Variability in outcomes after traumatic brain injury in children: a developmental perspective. In: Broman SH, Michel ME, eds. Traumatic head injury in children. New York: Oxford University Press, 1995:3-21.

3 Jaffe KM, Polissar NL, Fay GC, et al. Recovery trends over three years following pediatric traumatic brain injury. Arch Phys Med Rehabil 1995;76:17-26.

4 Klonoff H. Head injuries in children: predisposing factors, accident conditions, accident proneness and sequelae. Am J Public Health 1971;61:2405-17.

5 Levin H, Eisenberg H. Neuropsychological impairment after closed head injury in children and adolescents. J Pediatr Psychol 1979;4:389-402.

6 Rutter M, Chadwick O, Shaffer D, et al. A prospective study of children with head injuries: I. Design and methods. Psychol Med 1980;10:633-46.

7 Groom KN, Shaw TG, O'Connor ME, et al. Neurobehavioral symptoms and family functioning in traumatically brain-injured adults. Arch Clin Neuropsychol 1998;13:695-711.

8 McKinlay WW, Brooks DN, Bond MR, et al. The short-term outcome of severe blunt head injury as reported by relatives of the injured person. J Neurol Neurosurg Psychiatry 1981;44:527-33.

9 Anderson V, Moore C. Age at injury as a predictor of outcome following pediatric head injury. Child Neuropsychology 1995;1:187-202.

10 Anderson V, Morse SA, Klug G, et al. Predicting recovery from head injury in school-aged children: a prospective analysis. J Int Neuropsychol Soc 1997;3:568-80.

11 Dennis M. Language and the young damaged brain. In: Boll T, Bryant B, eds. Clinical neuropsychology and brain function: research, measurement and practice. Washington: American Psychological Association, 1989:85-124.

12 Ewing-Cobbs L, Fletcher J, Levin H, et al. Longitudinal neuropsychological outcome in infants and preschoolers with traumatic brain injury. $J$ Int Neuropsychol Soc 1997;3:581-91.

13 Gronwall D, Wrightson P, McGinn V. Effect of mild head injury during the preschool years. J Int Neuropsychol Soc 1997;3:592-7.

14 Taylor HG, Alden J. Age-related differences in outcomes following childhood brain insults: an introduction and overview. J Int Neuropsychol Soc 1997:3:555-67.

15 Rivara JB, Jaffe KM, Fay GC, et al. Family functioning and injury severity as predictors of child functioning one year following traumatic brain injury. Arch Phys Med Rehabil 1993;74:1047-55.

16 Rivara JB, Jaffe KM, Polissar NL, et al. Family functioning and children's academic performance in the year following traumatic brain injury. Arch Phys Med Rehabil 1994;75:369-79.

17 Perrot SB, Taylor HG, Montes JL. Neuropsychological sequelae, family stress, and environmental adaptation following pediatric head injury. Dev Neuropsychol 1991;7:69-86.

18 Brooks N. Closed head injury: psychological, social and family consequences. Oxford: Oxford University Press.

19 Taylor HG, Drotar D, Wade S, et al. Recovery from traumatic brain injury in children: the importance of the family. In: Broman S, Michel ME, eds. Traumatic head injury in children. New York: Oxford University Press, 1995:188-218.

20 Hall KM, Karzmark P, Stephens $M$, et al. Family stressors in traumatic brain injury: a two year follow-up. Arch Phys Med Rehabil 1994;75:876-83.

21 Fletcher J, Ewing-Cobbs L, Miner ME, et al. Behavioral changes after closed head injury in children. J Consult Clin Psychol 1990;58:93-8.

22 Anderson V, Northam E, Wrennall J, et al. Developmental neuropsychology: a clinical approach. Hove: Psychology Press, 2001.

23 Bohnert A, Parker J, Warschausky S. Friendship and social adjustment following traumatic brain injury: an exploratory investigation. Dev Neuropsychol 1997; 13:477-86.

24 Andrews T, Rose F, Johnson D. Social and behavioural effects of traumatic brain injury in children. Brain Inj 1998;12:133-8. 
25 Schwartz M, Taylor HG, Drotar D, et al. Long-term behavior problems following pediatric traumatic brain injury: prevalence, predictors and correlates. J Pediatr Psychol 2003;28:251-63.

26 Anderson V, Catroppa C, Haritiou F, et al. Predictors of acute child and family outcome following traumatic brain injury in children. Pediatr Neurosurg 2001;34:138-48

27 Taylor HG, Yeates K, Wade S, et al. A prospective study of short- and long term outcomes after traumatic brain injury in children: behavior and academic achievement. Neuropsychology 2002;16:15-27.

28 Breslau N. Does brain dysfunction increase children's vulnerability to environmental stress? Arch Gen Psychiatry 1990;47:15-20.

29 Rutter M, Chadwick O, Shaffer D. Head injury. In: Rutter M, ed. Developmental neuropsychiatry. New York: Guilford, 1983:83-111.

30 Brown G, Chadwick O, Shaffer D, et al. A prospective study of children with head injuries: III. Psychiatric sequelae. Psychol Med 1981;11:49-62.

31 Thomsen IV. Late outcome of very severe blunt head trauma: a 10-15 year second follow-up. J Neurol Neurosurg Psychiatry 1984;47:260-8.

32 Wade S, Taylor HG, Drotar D, et al. Childhood traumatic brain injury: initial impact on the family. J Learn Disabil 1996;29:652-66.

33 Rivara J, Fay G, Jaffe K, et al. Predictors of family functioning one year following traumatic brain injury in children. Arch Phys Med Rehabil 1992;73:899-910.

34 Prior M, Kinsella G, Sawyer M, et al. Cognitive and psychosocial outcomes after head injury in childhood. Austral Psychol 1994;29:116-23.

35 Brink J, Imbus C, Woo-Sam J. Physical recovery after closed head trauma in children and adolescents. J Pediatr 1980;97:721-7.

36 Max J, Castillo C, Robin D, et al. Predictors of family functioning following traumatic brain injury in children and adolescents. J Am Acad Child Adolesc Psychiatry 1997;36:83-90.

37 Anderson-Parente JK, DiCesare A, Parente R. Spouses who stayed. Cognitive Rehabilitation 1990;8:22-5.

38 Max J, Castillo C, Robin D, et al. Predictors of family functioning after traumatic brain injury in children and adolescents. J Am Acad Child Adolesc Psychiatry 1998;37:83-90.
39 Teasdale G Jennet B. Assessment of coma and impaired consciousness. Lancet 1974;2:81-4.

40 Jennet $B$, Bond $M$. Assessment of outcome after severe brain damage. Lancet 1975;i:480-4.

41 Daniel A. Power, privilege and prestige: occupations in Australia. Melbourne: Longman-Cheshire, 1983.

42 Sparrow S, Balla D, Cicchetti D. The Vineland adaptive behavior scales: interview edition, survey form manual. Circle Pines, Minnesota: American Guidance Services, 1984.

43 Rowe KJ, Rowe KS. The relationship between inattentiveness in the classroom and reading achievement. J Am Acad Child Adolesc Psychiatry 1992;31:357-68.

44 Lachar D. Personality inventory for children (PIC) (revised formal manual supplement). Los Angeles CA: Western Psychological Services, 1992.

45 Noller P. ICPS Family Functioning Scales. Unpublished manuscript. University of Queensland, 1988.

46 Wechsler D. Manual for the preschool and primary intelligence scale-revised. New York: Psychological Corporation, 1987

47 Wechsler D. Manual for the Wechsler scale of children's intelligence. Version III. New York: Psychological Corporation, 1991.

48 Kaufman A. Intelligent testing with the WISC-R. New York: John Wiley \& Sons, 1979.

49 Anderson VA, Lajoie G, Bell R. Neuropsychological assessment of the school aged child. Melbourne: University of Melbourne, 1995.

50 Christensen A. Luria's neuropsychological investigation. Munksgard, Denmark: Schmidts Bobtrykkeri Vogens, 1979.

51 Lhermitte J, Signoret JL. Analyse neuropsychologique et differenciation des syndromes amnesiques. Revue Neuropsychologique 1972;74:20-38.

52 Adams W, Sheslow D. Manual for the wide range assessment of memory and learning test. Wilmington: Jastak, 1989.

53 Asarnow R, Satz P, Light R, et al. Behavior problems and adaptive functioning in children with mild and severe closed head injury. J Pediatr Psychol $1991 ; 16: 543-55$. 